
Pathophysiology of Haemostasis and Thrombosis

\title{
Quantification of Antithrombin Isoform Proportions in Plasma Samples of Healthy Subjects, Sepsis Patients, and in Antithrombin Concentrates
}

\author{
J ürgen Römischa Reiner Dönges ${ }^{a}$ Harald Stauss ${ }^{a}$ Dietrich Inthorn ${ }^{b}$ \\ Dieter Mühlbayerc Marianne J ochum ${ }^{d}$ J ohannes N. Hoffmann ${ }^{b}$ \\ ${ }^{a}$ Aventis Behring $\mathrm{GmbH}$, Research, Marburg, Departments of ${ }^{b}$ Surgery and cClinical Chemistry, \\ University Hospital Grosshadern, and dDivision of Clinical Chemistry and Clinical Biochemistry, \\ Department of Surgery (City), Ludwig Maximilian University of Munich, Munich, Germany
}

\author{
Key Words \\ Antithrombin - Isoform proportion - AT- $\alpha \cdot$ AT- $\beta \cdot$ AT \\ concentrates - AT metabolism
}

this novel quantitative AT isoform assay allows, for the first time, a closer look at the role of AT isoforms in hemostasis and sepsis pathophysiology.

Copyright $\odot 2002$ S. Karger AG, Basel

\begin{abstract}
Antithrombin (AT) circulates in plasma in two isoforms, AT- $\alpha$ (90-95\%) and AT- $\beta$ (5-10\%). AT isoform proportions were measured in plasma samples of 17 healthy subjects and 26 posttraumatic or postoperative septic patients, as well as in 4 commercially available AT concentrates. Total AT was immune-purified from plasma and concentrates. Micellar electrokinetic chromatography was used to analytically separate and quantify the isoforms. Compared with plasma samples of healthy donors, septic plasmas revealed significantly reduced AT activity $(p<0.001)$ and $\beta$-isoform content $(p<0.05)$. AT- $\beta$ correlated inversely with urea and creatinine serum concentrations ( $p<0.01$ ), indicating a relationship between better renal function and higher $\beta$-isoform content. $\beta$-Isoform neither correlated with age, gender, and 28-day mortality, nor with plasma concentrations of various inflammatory and organ function parameters. The commercial AT concentrate, which is equivalent to the current WHO standard, had an AT- $\beta$ content close to that found in plasma of healthy subjects. The availability of
\end{abstract}

\section{Introduction}

Antithrombin (AT) is one of the most important protease inhibitors in plasma-regulating blood coagulation $[1,2]$. In healthy subjects, AT circulates in two isoforms, AT- $\alpha(90-95 \%)$ and AT- $\beta$ (5-10\%). AT- $\beta$, lacking a carbohydrate chain close to the heparin binding site, has a higher affinity to heparin and other glycosaminoglycans [3-6]. As glycosaminoglycans (GAGs) accelerate the interaction of AT with its target proteases like thrombin and factor $\mathrm{Xa}$, it is assumed that the $\beta$-isoform constitutes the more important part of AT, acting as first 'shield of defense' against proteolytic imbalance [7, 8]. Furthermore, GAGs serve as cell surface- and matrix-binding partners for AT. In vitro and in vivo studies showed the $\beta$-isoform to be primarily colocalized with GAGs $[7,9$, $10]$. In the absence of GAGs, the $\beta$-isoform appears to be a better inhibitor of factor IXa and factor Xa than AT- $\alpha$ $[11,12]$.

\section{KARGER \\ Fax +4161306 1234 \\ E-Mail karger@karger.ch \\ www.karger.com

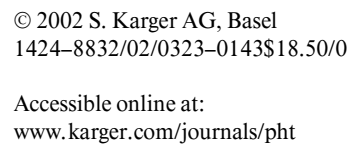

Dr. Jürgen Römisch

Octapharma Pharmazeutika Produktionsges. m.b.H.

Oberlaaer Strasse 235, A-1100 Vienna (Austria)

Tel. +431610 32251, Fax +43161032330

E-Mail Juergen.Roemisch@octapharma.at 
In clinical states like disseminated intravascular coagulation (DIC), trauma, shock and sepsis, all associated with massive injury of the vessel wall, rapid AT consumption is observed [13-16]. As decreased AT plasma levels correlate with increased mortality, the concept of exogenous AT substitution has been established [17-21]. Due to the lack of suitable quantification methods, neither sound data on potential alterations of plasma AT isoform patterns during septic states, nor information on AT isoform proportions in different AT concentrates have become available so far. This paper reports on the suitability of micellar electrokinetic chromatography to quantify AT isoforms in complex protein solutions, in particular after immune adsorption of total AT. We also looked for potential therapeutic and pathophysiological roles for AT isoforms, as AT- $\beta$ isoform content is correlated with clinically important parameters of organ function and plasma parameters of septic inflammatory response.

\section{Material and Methods}

Cyclodextrin-Modified Micellar Electrokinetic Chromatography

Cyclodextrin-modified micellar electrokinetic chromatography (CD-MEKC) was used to analytically separate AT- $\alpha$ and $-\beta$. Separation in capillary zone electrophoresis is based on the differences in electrophoretic mobility, resulting in different migration velocities of ionic species in the electrophoretic buffer contained in the capillary. MEKC is a high-resolution technique providing an additional selectivity mechanism [22-24]. It is based on micellar solubilization and electrophoretic migration of the micelle, i.e., the solutes are separated by the differential distribution between the micelle and the surrounding aqueous phase, as well as the differential migration of the two phases. By using surfactant micelles, a charged vehicle is provided to perform an electrophoretic separation of both neutral and charged solutes. The separation process of the solutes between micelles can be influenced by chiral selectors like cyclodextrins [25]. A 270A-HT Capillary Electrophoresis System (Applied Biosystems, USA), equipped with a monochromatic UV detector and a polyimidecoated fused silica capillary (50 cm effective length, $50 \mu \mathrm{m}$ i.d. $\times 363$ $\mu \mathrm{m}$ o.d., Supelco, USA) was used. Separations were run in $0.06 \mathrm{M}$ boric acid, $0.04 M$ sodium dodecylsulphate, $0.02 M \beta$-cyclodextrin, $0.001 M$ diaminopentane, at a $\mathrm{pH}$ of 9 . Solutions $(0.5-5 \mathrm{nl})$ containing $0.1-1.0 \mathrm{mg} / \mathrm{ml}$ AT were applied. Quantification of isoforms was performed by peak area integration. The technique has recently been described in more detail [26].

AT Isoform Determination in Complex Protein Solutions

Separation of AT Isoforms and Validation of MEKC Analysis. AT III isoforms were prepared from AT III concentrate (Kybernin ${ }^{\circledR} \mathrm{P}$, Aventis Behring GmbH, Germany) by adsorption to Heparin-Fractogel ${ }^{\circledR}$. Twenty thousand units of AT III were dissolved in 2.0 liters of water for injection (WFI) and pumped onto the heparin column (500 $\mathrm{ml}$ ), which had been equilibrated with $0.015 M \mathrm{Na}_{2} \mathrm{H}\left(\mathrm{PO}_{4}\right)-2$ hydrate, $0.06 \mathrm{M} \mathrm{NaH}_{2}\left(\mathrm{PO}_{4}\right)$-2-hydrate, $0.05 \mathrm{NaCl}$, pH 7.2.
The $\alpha$-isoform of AT was obtained by increasing the ionic strength up to $0.8 \mathrm{M} \mathrm{NaCl}$ in equilibration buffer, whereas the $\beta$-AT isoform was eluted with $2 \mathrm{M} \mathrm{NaCl}$. Both preparations were dialyzed against $0.01 M$ Na-citrate, $0.15 M \mathrm{NaCl}$, pH 7.4. Concentrations were adjusted according to the respective heparin cofactor activity or AT protein (at $150 \mu \mathrm{g} / \mathrm{IU}$ AT). It had been ensured that the described procedure had no denaturing impact on the preparations. On average, $97 \%$ of the AT solution (activity) applied to the column was recovered.

Beside the characteristic that the $\beta$-isoform displays a higher affinity to heparin and therefore elutes at higher ionic strength, it was analytically identified by SDS-PAGE and isoelectric focusing, as described by other working groups [4-7, 26]. Both methods, but in particular the first, provide semi-quantitative methods for the differentiation of both isoforms.

Purified isoforms as well as defined mixtures were used to validate the MEKC conditions, as described below and as recently reported in more detail [27].

In general, AT activities were quantified using the Berichrom ${ }^{\circledR}$ AT assay (Dade Behring GmbH, Germany). AT antigen concentrations of flow-through and eluate fractions were determined employing an ELISA (Kordia BV, The Netherlands).

\section{Purification of AT from AT Concentrates and Human Plasmas}

Prior to MEKC analysis, AT was purified from plasma by immune-adsorption to a monoclonal antibody (mAb-5) bound to BrCN-Sepharose ${ }^{\circledR}$ (Amersham Pharmacia Biotech AB, Sweden).

$\mathrm{mAb}-5$ directed against AT has been demonstrated to bind both isoforms with comparable affinity, employing plasmon resonance technique using a Biacore ${ }^{\circledR}$ system. Association/dissociation constants were calculated according to the equipment provider's instructions: for AT- $\alpha$ and AT- $\beta$ we found KA values of $1.91 \times 10^{8} M^{-1}$ $\left(\mathrm{K}_{\text {ass }}: 5.46 \times 10^{4} M^{-1} \times \mathrm{s}^{-1} ; \mathrm{K}_{\text {diss: }}: 2.86 \times 10^{-4} M^{-1} \times \mathrm{s}^{-1}\right)$ and 1.87 $\times 10^{8} M^{-1}\left(\mathrm{~K}_{\text {ass }}: 5.52 \times 10^{4} M^{-1} \times \mathrm{s}^{-1}\right.$; $\mathrm{K}_{\text {diss }}: 2.95 \times 10^{-4} M^{-1} \times$ $\left.\mathrm{s}^{-1}\right)$, respectively. This $\mathrm{mAb}$ was used for the following experiments. Solutions $(0.5 \mathrm{ml})$ containing $50 \mathrm{IU} / \mathrm{ml}$ of AT- $\alpha$, AT- $\beta$ or different mixtures thereof in $0.01 \mathrm{M}$ Na-citrate, $\mathrm{pH} 7.5$, were pumped onto immune-adsorbent columns ( $10 \mathrm{ml}$ at $1 \mathrm{mg} \mathrm{mAb}-5 / \mathrm{ml}$ of gel each). After washing the columns with $0.01 M$ Tris, $1.0 \mathrm{M} \mathrm{NaCl}$, pH 8.0, AT was eluted with $0.1 \mathrm{M}$ glycine, $\mathrm{pH} 2.5$. The eluates were immediately adjusted to $\mathrm{pH} 7.5$ by addition of a sufficient volume of $1.0 \mathrm{M}$ Tris, $\mathrm{pH}$ 9.0. Column flow-through fractions, wash solutions and eluates were tested for AT activity and by MEKC. mAb-5 was identified as suitable for immune adsorption in terms of recovery of activity and $\alpha-\beta$ content compared with the raw material (table 1). Initial SDSPAGE runs and MEKC investigation revealed that AT- $\alpha$ contained only $0.8 \%$ of residual AT- $\beta$, whereas the AT- $\beta$ preparation contained about $3 \%$ of the $\alpha$-isoform (not shown). These baseline contents were taken into consideration when calculating the recovery after immunoadsorption (i.e. were subtracted from the total content found).

Column overloading experiments had been performed in order to ensure that the isoform proportions of the samples applied were not altered by the immune-adsorption procedure. Increasing amounts $(25,50,100,250$ IU AT per column) of an AT solution containing $10 \%$ AT- $\beta$ were applied to the mAb- 5 columns. Eluates were analyzed as described above. When exceeding 25 IU of total AT applied, the column flow-throughs (FT) contained increasing AT activity, as expected. The AT- $\beta$ content of the eluates (and the FT fractions), however, did not change significantly and did not decrease with increasing total amounts applied (eluates: mean 9.6, SD 0.2, range
Römisch/Dönges/Stauss/Inthorn/

Mühlbayer/Jochum/Hoffmann 
Table 1. Evaluation of the immune adsorption step prior to MEKC

\begin{tabular}{|c|c|c|c|c|c|}
\hline \multirow[t]{2}{*}{ Sample } & \multirow{2}{*}{$\begin{array}{l}\text { AT- } \beta \text { content } \\
\text { spiked }\end{array}$} & \multicolumn{2}{|c|}{ Recovery in eluate activity } & \multicolumn{2}{|c|}{ AT- $\beta$ content measured } \\
\hline & & mean & SD & mean & SD \\
\hline AT- $\alpha$ & 0.8 & 87.5 & 3.1 & 0.8 & 0.01 \\
\hline AT $-\beta$ & 97.0 & 89.0 & 2.2 & 97.0 & 0.5 \\
\hline AT- $\alpha /$ AT- $\beta$ & 2.0 & 90.1 & 2.8 & 1.9 & 0.05 \\
\hline AT- $\alpha /$ AT $-\beta$ & 5.0 & 88.3 & 1.1 & 5.1 & 0.1 \\
\hline AT- $\alpha /$ AT- $\beta$ & 10.0 & 86.4 & 2.5 & 10.5 & 0.2 \\
\hline AT- $\alpha /$ AT $-\beta$ & 15.0 & 87.9 & 3.3 & 14.2 & 1.3 \\
\hline AT- $\alpha /$ AT- $\beta$ & 50.0 & 92.3 & 3.0 & 47.7 & 2.3 \\
\hline
\end{tabular}

All figures are percentages.
9.3-10.0\%). Furthermore, increasing volumes of citrated plasma samples were immune adsorbed and treated as described above. Again we found no significant drift in isoform ratios (not shown). We used AT-deficient plasma (DP, in-house) as control, which revealed a residual AT activity of $<0.5 \%$ (compared with the reference plasma); AT- $\beta$ was not detectable in the DP. Spiking experiments of purified isoform mixtures in the DP revealed recoveries of $>90 \%$ of activity and $>95 \%$ of the AT- $\beta$ content expected.

AT concentrates from Aventis Behring, Grifols (Germany), Baxter (Germany) and Pharmacia Upjohn (Germany) were investigated, three of which revealed high purity. As we observed a peak overlap of another plasma protein with that of the $\beta$-isoform upon MEKC of the less pure concentrate $\mathrm{C}$, prior immune adsorption became necessary. As a consequence, all concentrates were processed equivalently. AT from standard human plasma (SHP), representing a pool of more than 100 healthy donors, was purified accordingly.

Three milliliters of $\mathrm{mAb}$-Sepharose $(5 \mathrm{mg} \mathrm{mAb}-5 / \mathrm{ml}$ gel $)$ were used to prepare AT from 1 to $3 \mathrm{ml}$ of the respective citrated plasma sample, which had been diluted 10 -fold in $0.15 \mathrm{M}$ saline beforehand. After washing of the mAb resin with 25 column volumes each of 0.01 $M$ Tris/ $\mathrm{HCl}$ containing $2 M \mathrm{NaCl}, \mathrm{pH} 8.5$, and water, AT was eluted with a solution of $0.1 \mathrm{M}$ glycine, at a $\mathrm{pH}$ of 2.5. The eluates were adjusted to $\mathrm{pH}$ 7.0-7.4 immediately and were concentrated by ultrafiltration ( $5 \mathrm{kD}$ filter, Millipore, USA) to $0.1-1.0 \mathrm{mg} / \mathrm{ml}$ of total protein. In parallel, the buffer was exchanged to $0.01 M$ sodium-citrate, $0.15 \mathrm{M} \mathrm{NaCl}, \mathrm{pH} 7.4$, and the AT solutions were subjected to MEKC thereafter.

\section{Blood Sampling and Quantification of Organ Dysfunction and} Inflammatory Response

Citrated blood and serum were drawn from 17 healthy donors (10 male, 7 female; mean age: $43.2 \pm 11.8$ years) and from posttraumatic and postoperative patients ( 18 male, 8 female; mean age: $61.3 \pm 13.8$ years) on admission to the surgical intensive care unit of the Munich University Hospital Grosshadern due to severe sepsis, as defined by the consensus criteria [17]. Underlying diseases were malignancies (16), obstructive pulmonary disease (3) and polytrauma (7). Severity of organ dysfunction was assessed by the measurement of hematological and clinical chemistry tests, as well as by blood gas analysis. Pulmonary gas exchange was expressed as the $\mathrm{PaO}_{2} / \mathrm{FiO}_{2}$ ratio, as has been described previously [17]. This ratio is an appropriate measure of pulmonary function at different levels of inspired oxygen concentration and positive end-expiratory pressure ventilation [17]. To quantify liver dysfunction, we determined serum concentrations of bilirubin [17]. Kidney function was estimated by the determination of urea and creatinine concentrations by routine laboratory procedures (normal urea values: $<50 \mathrm{mg} / \mathrm{dl}$; creatinine: $<1.0 \mathrm{mg} / \mathrm{dl}$ ). No patient had continuous renal replacement therapy or chronic renal failure.

Ten out of the 26 patients suffered from DIC, which was defined by fulfilling 3 out of the 4 the following criteria: concentration of serum fibrinogen $<1.5 \mathrm{~g} / \mathrm{l}$; platelet count $<150 \mathrm{G} / \mathrm{l}$; partial thromboplastin time: $>45 \mathrm{~s}$; prothrombin time: $<60 \%$ of normal [17].

In order to quantify the inflammatory response and investigate potential relationships with AT- $\beta$ content, interleukin-6 (IL-6), interleukin 8 (IL-8), circulating intercellular adhesion molecule-1 (ICAM1), E-selectin, and PMN elastase were determined by using commercially available ELISA kits according to the manufacturers' instructions (IL-6: R \& D Systems, USA; IL-8: Amersham, Germany; soluble ICAM-1 and E-selectin: Serva/Bender, Germany; PMN elastase: Merck, Germany). Normal values given by the manufacturers are: IL-6: 0-6 pg/ml; IL-8: 0-30 pg/ml; ICAM-1: 180-280 ng/ml; Eselectin: $15-25 \mathrm{ng} / \mathrm{ml}$; PMN elastase: $80-120 \mathrm{ng} / \mathrm{ml}$.

\section{Statistics}

Data are presented as mean values and standard deviations (SD). AT activity and $\beta$-isoform content between 2 groups were compared by the unpaired Student's t test or the unpaired Wilcoxon rank test where appropriate. A one-way analysis of variance with appropriate post hoc tests was used to compare AT activity and isoforms in more than 2 groups. Spearman correlation coefficients (two-tailed significances) were calculated by the SPSS software package (SPSS, version 10.0 , Chicago, USA). A significance level of $\mathrm{p}<0.05$ was chosen to indicate statistical significance.

\section{Results}

\section{Quantification of AT- $\beta$ Isoform Levels by CD-MEKC}

Using CD-MEKC under the conditions described, a sufficient separation of the isoforms was achieved in order to quantify AT- $\alpha$ and $-\beta$. Although an estimation of total AT concentrations is possible with this method, we were mainly interested in the proportion of the isoforms, 

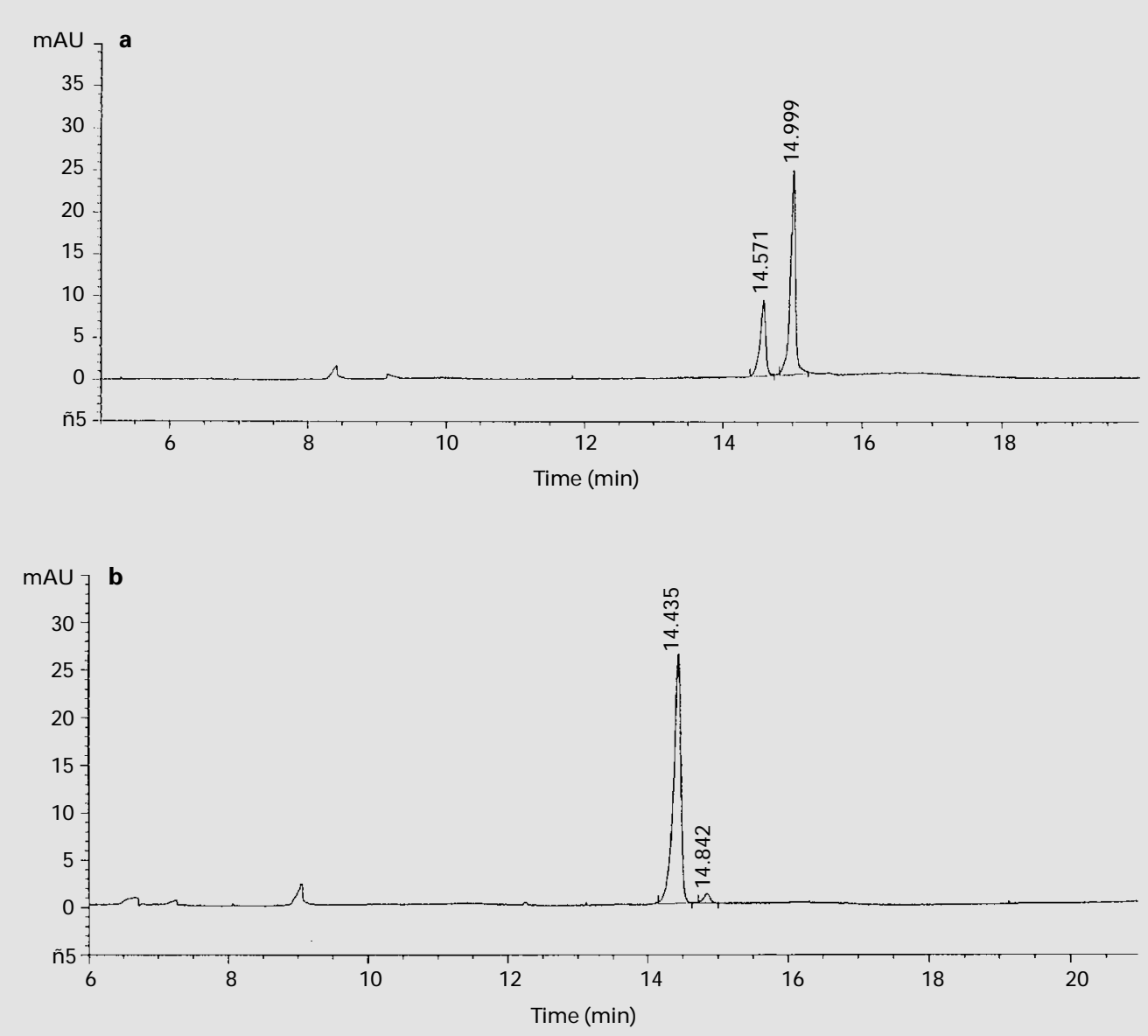

Fig. 1. Electropherograms of AT isoform separations by CD-MEKC

which was expressed as percent AT- $\beta$ content of total AT ( $\alpha$ - plus $\beta$-isoforms). Spiking experiments showed that a quantification covering a broad proportion range was possible. Exemplary separation electropherograms of a mixture of the purified isoforms $(30 \% \alpha-$ and $70 \% \beta$ isoform) and of a high purity AT concentrate are shown (fig. 1a, b).

\begin{tabular}{|c|c|c|c|c|}
\hline No. & PET & Height & Area & Area \% \\
\hline \multicolumn{5}{|c|}{ a Purified AT- $\alpha(30 \%)$ and $-\beta(70 \%)$ mixture } \\
\hline 1 & 14.571 & 9.018 & 51.631 & 29.520 \\
\hline 2 & 14.999 & 23.973 & 123.273 & 70.480 \\
\hline \multicolumn{5}{|c|}{ b AT concentrate } \\
\hline 1 & 14.435 & 26.261 & 195.948 & 96.594 \\
\hline 2 & 14.842 & 1.014 & 6.909 & 3.406 \\
\hline
\end{tabular}

PET $=$ Peak elution time.

AT Activity and $\beta$-Isoform Content of Plasma Samples and Standard Human Plasma

The evaluation of 17 plasma samples of healthy subjects revealed a mean AT activity of $0.99 \mathrm{IU} / \mathrm{ml}$ (SD: 0.08 $\mathrm{IU} / \mathrm{ml}$ ), ranging from 0.87 to $1.12 \mathrm{IU} / \mathrm{ml}$. Pool plasma (SHP; $>100$ donations) had an activity of $1.0 \mathrm{IU} / \mathrm{ml}$ by definition. Septic plasmas $(n=26)$ displayed a significant- 
ly $(\mathrm{p}<0.0001)$ reduced AT activity, with a mean level of $0.65 \mathrm{IU} / \mathrm{ml}$ (SD: $0.2 \mathrm{IU} / \mathrm{ml}$ ), ranging from 0.3 to $1.1 \mathrm{IU} /$ $\mathrm{ml}$.

AT of each plasma sample was obtained by separate immune adsorption prior to MEKC. In pre-experiments, the eluates were investigated on AT activity in relation to AT protein (as determined by ELISA). Compared to the individual plasma samples, more than $95 \%$ of AT-specific activities were recovered after immune-adsorption, indicating that this procedure did not significantly harm AT.

Standard human plasma contained $7.4 \%$ AT- $\beta$. On average, plasma of healthy donors had a $7.8 \% \beta$-isoform content $( \pm 1.4 \% \mathrm{SD})$, ranging from 5.9 to $10.7 \%$, whereas plasma from septic patients showed a significantly reduced mean $6.6 \%$ AT- $\beta$ content $\pm 2.0 \%$ SD), ranging from 3.0 to $10.5 \%$ when compared to healthy donors' plasma pool $(\mathrm{p}=0.027)$. There was no correlation between AT activity and $\beta$-isoform content in the plasma samples from healthy donors and from sepsis patients (fig. 2).

When comparing sepsis patients without DIC with those suffering from DIC, as defined by Inthorn et al. [17], there were no significant differences in AT activity (nonDIC: $0.65 \pm 0.22 \mathrm{IU} / \mathrm{ml} \mathrm{SD}$, vs. DIC: $0.65 \pm 0.18 \mathrm{IU} / \mathrm{ml}$ SD) and AT- $\beta$ levels (non-DIC: $7.1 \pm 1.8 \%$ SD, vs. DIC: $6.5 \pm 2.0 \% \mathrm{SD})$.

\section{Correlation of AT- $\beta$ Isoform Content with Gender, Age, Clinical Outcome and Organ Function \\ Parameters}

We did not detect any difference between AT- $\beta$ contents in female and male healthy volunteers (female: 7.9 $\pm 1.2 \% \mathrm{SD}$, male: $7.8 \pm 1.8 \% \mathrm{SD}$ ) or female and male septic patients (female: $6.5 \pm 2.7 \% \mathrm{SD}$, male: $5.6 \pm 1.5 \%$ $\mathrm{SD})$. No correlation was found between $\beta$-isoform content and age in healthy volunteers and septic patients $(\mathrm{r}=$ $-0.22 ; p=0.27)$. AT $-\beta$ content did not significantly differ between patients who survived 28 days and patients who died within this period (alive at day 28: $6.3 \pm 1.7 \% \mathrm{SD}$; died before day 28: $5.3 \pm 2.2 \% \mathrm{SD}$ ), or between patients who survived and those who died (survivors: $6.6 \pm 1.9 \%$ SD; non-survivors: $5.7 \pm 1.9 \% \mathrm{SD}$ ).

We did neither observe a correlation between AT- $\beta$ content and $\mathrm{PaO}_{2} / \mathrm{FiO}_{2}$ ratio $(\mathrm{r}=-0.26, \mathrm{p}=0.27)$ nor AT$\beta$ and serum bilirubin $(r=0.06, p=0.78)$. However, inverse correlations of both, AT- $\beta$ content and serum creatinine $(r=-0.41, p<0.05)$, as well as AT- $\beta$ content and serum urea $(\mathrm{r}=-0.65, \mathrm{p}<0.001)$ were observed (fig. 3a, b).

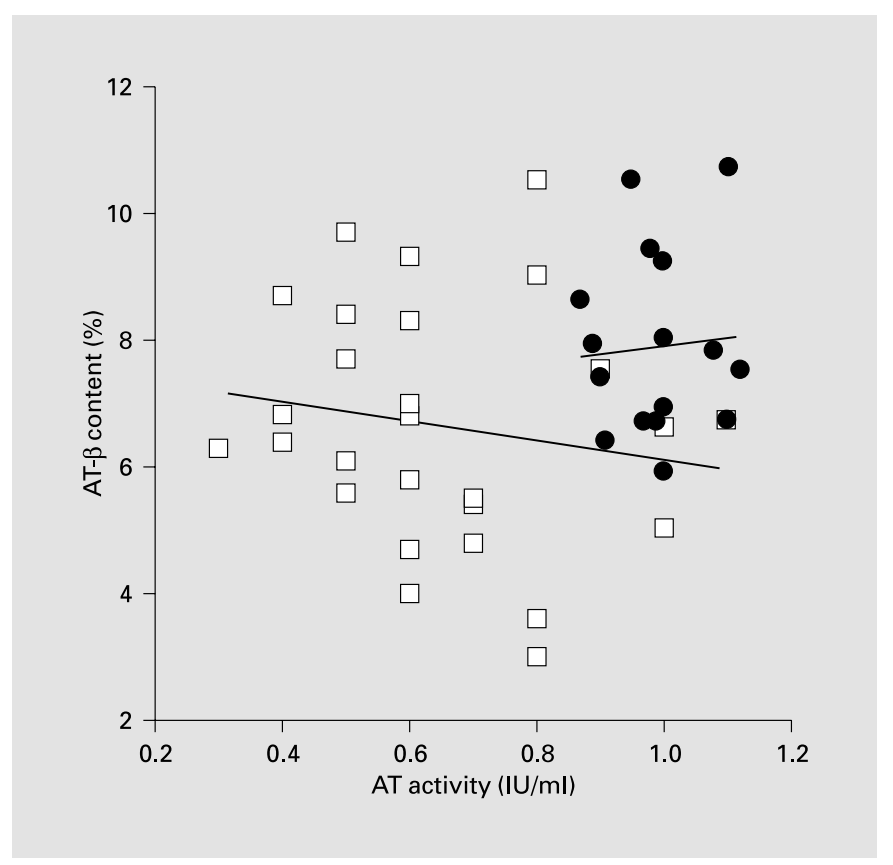

Fig. 2. Correlation of AT activity and AT- $\beta$ content in plasma of healthy $(\mathrm{n}=17)$ and septic patients $(\mathrm{n}=26)$. $\mathbf{O}=$ Healthy controls; $\square=$ septic patients.

\section{Correlation of AT- $\beta$ Isoform Content and Parameters of Inflammatory Response in Septic Patients}

At the time of sepsis diagnosis, we did not observe a significant correlation between IL-6 and IL- 8 concentrations and AT- $\beta$ content (IL- $6: \mathrm{r}=-0.24, \mathrm{p}=0.41 ;$ IL-8: $\mathrm{r}=$ $-0.33, p=0.25)$. Neither soluble ICAM-1 and E-selectin concentrations nor elastase contents related with circulating AT- $\beta$ levels (ICAM-1: $r=-0.13, p=0.60$; E-selectin: $\mathrm{r}=-0.22, \mathrm{p}=0.44$; PMN elastase: $\mathrm{r}=-0.08, \mathrm{p}=0.72$ ).

\section{AT- $\beta$ Isoform Content in Different AT Concentrates}

Considerable differences in the $\beta$-isoform content of 4 investigated commercially available AT concentrates were found. Concentrate A ( $\mathrm{n}=27$ lots) had an average AT- $\beta$ content of $5.2 \%$, concentrate B of $1.7 \%$ (SD: $1.0 \%$, range: $0.3-3.1 \%$ ), $\mathrm{C}$ of $3.9 \%$ and $\mathrm{D}$ of $2.2 \%$ (table 2 ). While all concentrates showed, on average, lower AT- $\beta$ isoforms than the plasma of healthy donors $(p<0.01)$, concentrate A contained significantly $(\mathrm{p}<0.01)$ more AT$\beta$ than the other products. AT- $\beta$ in concentrate $C$ was significantly $(p<0.01)$ higher than in concentrates $B$ and $D$, whereas the two latter did not differ significantly $(p=0.3)$ from each other. 

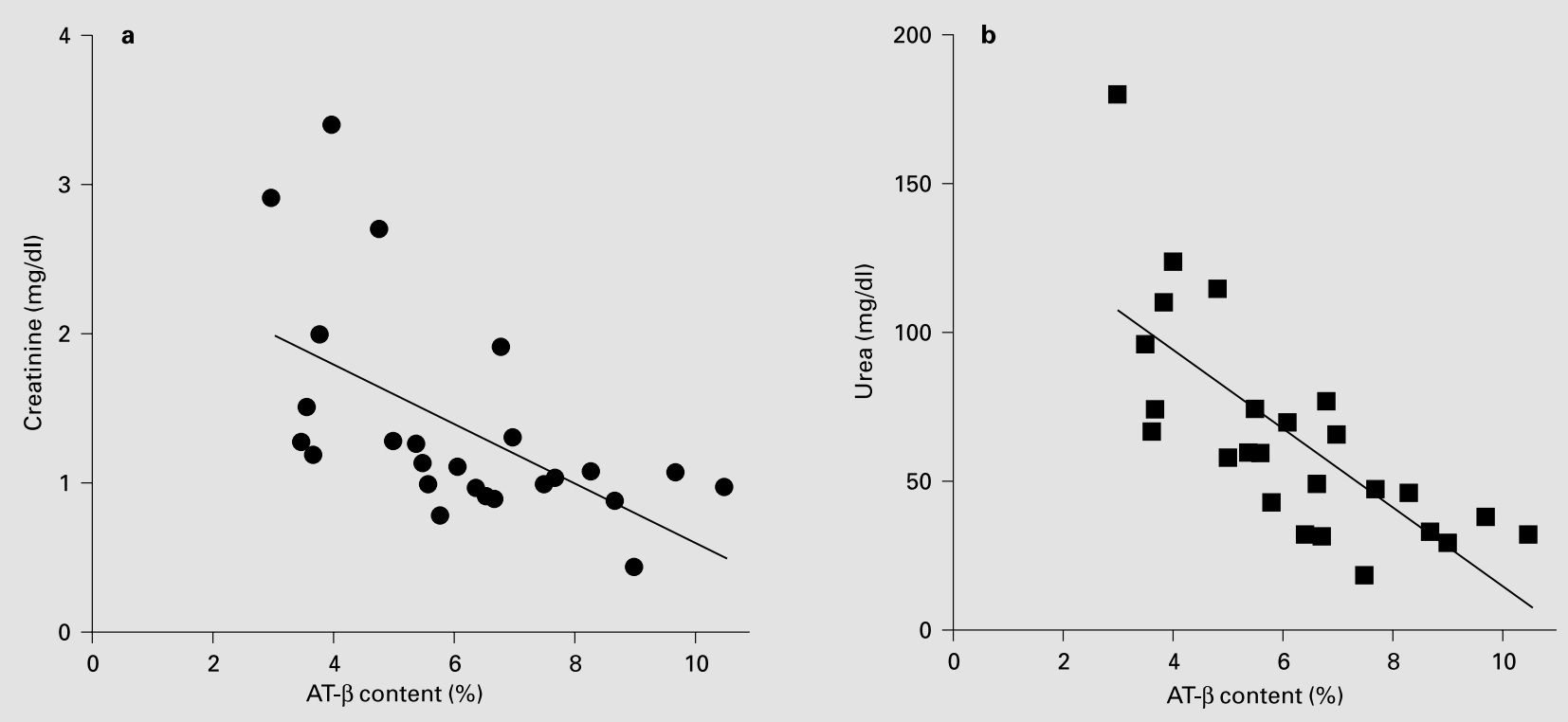

Fig. 3. Correlation of AT- $\beta$ content with creatinine (a) and urea (b) concentrations in plasma of septic patients $(n=26)$.

Table 2. AT- $\beta$ contents of four AT concentrates

\begin{tabular}{|c|c|c|c|c|c|}
\hline \multirow[t]{2}{*}{ Concentrate } & \multicolumn{3}{|c|}{ AT- $\beta$ content } & \multirow[t]{2}{*}{$\mathrm{p}$ value } & \\
\hline & mean value & SD & range & & \\
\hline$A, n=27$ & 5.2 & 0.7 & $4.3-6.7$ & A vs. B, C, D: & $\mathrm{p}<0.01$ \\
\hline $\mathrm{B}, \mathrm{n}=12$ & 1.7 & 1.0 & $0.3-3.1$ & B vs. D: & $\mathrm{p}=0.3$ \\
\hline $\mathrm{C}, \mathrm{n}=8$ & 3.9 & 0.7 & $3.3-5.5$ & C vs. B, D: & $\mathrm{p}<0.01$ \\
\hline $\mathrm{D}, \mathrm{n}=11$ & 2.2 & 0.9 & $1.1-3.9$ & & \\
\hline
\end{tabular}

Unless otherwise stated, all figures are percentages.

\section{Discussion}

Recently we reported about CD-MEKC allowing the exact determination of AT isoform proportions in albumin-diluted solutions or high-purity AT concentrates without further processing [26]. This method provides an advantage over other electrophoretic methods reported [27]. In complex protein solutions it is, however, necessary to isolate AT by immune adsorption beforehand.

AT isoform proportions in plasma samples of healthy subjects, septic patients, and AT concentrates were expressed as percent AT- $\beta$. The measured AT- $\beta$ levels in healthy subjects, ranging from 5.9 to $10.7 \%$, are in line with the results reported by other working groups, using gel electrophoresis and scanning of stained protein bands. Besides, the mean value of $7.8 \%$ found in healthy volunteers agrees well with $7.4 \%$ measured in SHP, which represents a pool of more than 100 healthy donors.

The biological importance of the AT- $\beta$ isoform was stressed by a recent publication on a family displaying an Asn135Thr AT mutation, which affects the consensus sequence responsible for the glycosylation close to the heparin binding site [28]. As a consequence, plasma of certain members of this family contains a significantly increased $\beta$-isoform content. As these subjects have not been suffering from thrombosis despite an AT activity of 
only $70 \%$, it was assumed that the greater AT- $\beta$ content may have provided a protective effect due to its probably more efficient anticoagulant properties. Thus, according to the current hypothesis that the $\beta$-isoform plays the predominant role in, for instance, thrombotic events, we supposed that AT- $\beta$ consumption during DIC might significantly affect the isoform proportion in plasma from septic patients.

Although the difference between healthy and sepsis plasma $\beta$-isoform content reached statistical significance $(p=0.027)$, the broad concentration ranges found in both groups overlapped to a certain extent. In fact, we did not find a correlation between AT consumption measured by decreasing AT activity and $\beta$-isoform content in septic plasma. Although we recently demonstrated that both AT isoforms were inactivated to the same extent by PMN elastase in vitro [12], we cannot exclude that proteolytic inactivation contributed to the correlation of decreasing AT activity and $\beta$-isoform contents in this study.

Furthermore, we tried to further elucidate the biological AT- $\beta$ importance by analyzing its correlation with well-established parameters of multiple organ dysfunction and pro-inflammatory response. Interestingly, we found a significant correlation between higher AT- $\beta$ content and improved kidney function, which was reflected by lower urea and creatinine plasma concentration. Since neither organ function parameters like bilirubin and $\mathrm{PaO}_{2} / \mathrm{FiO}_{2}$ ratio and 28-day mortality, nor hospital mortality or inflammatory mediator concentrations correlated with AT- $\beta$ content, the biological significance of this finding remains unclear at present. From our results, it may be speculated that increased AT- $\beta$ consumption in septic patients reflects a significantly enhanced AT metabolism, which is necessary to counteract multiple mediators and proteases released from endothelium and subendothelium upon diverse stimuli. Furthermore, it has to be considered that the number of patient samples analyzed was limited. The results reported have to be confirmed by a larger study in the future.

Sepsis and DIC are associated with high mortality. A recent clinical sepsis study suggested a clinical benefit (90day mortality) in a patient subgroup receiving AT without concomitant heparin [29]. Regarding clinically important differences between the available AT concentrates, only few clinical studies showing considerable differences in the in vivo AT recovery during supplementation have been published so far [30]. However, purity, which is a result from different production procedures, also differs considerably between different AT concentrates [31, 32]. According to our study, significant variations in the $\beta$ isoform contents of different concentrates are obvious. In concentrate $\mathrm{A}$, which is equivalent to the current $\mathrm{WHO}$ AT standard, $\beta$-isoform contents were found to be close to the average plasma levels of healthy donors [33], whereby concentrate A contained significantly higher amounts of AT- $\beta$ than concentrates B, C and D. In concentrates B and D we found minimal AT- $\beta$ levels - close to $1 \%$ or even below - reflecting differences in the manufacturing process, which includes heparin adsorption as the main purification step. Adsorption and elution conditions influence the yields of the $\beta$-isoform, as well as different plasma fractions used as raw material [34-36].

As a consequence, administration of AT concentrates with low AT- $\beta$ content might result in a systemic AT- $\beta$ depletion. However, the biological significance of AT- $\beta$ deficiency during different clinical states remains to be elucidated.

The availability of the new assay system for determination of AT isomer content now facilitates a closer look at the role of AT isoforms and their metabolism during homeostasis and under pathophysiological conditions.

\section{References}

1 Olds RJ, Lane DA, Mille BM, Chowdhury V, Path MRC, Thein SL, Path FRC: Antithrombin: Principal inhibitor of thrombin. Semin Thromb Hemostas 1994;20:353-372.

2 Risberg B: Antithrombin: Facts and new hypotheses. Blood Coagul Fibrinolysis 1998; 9(suppl 3):S3-S6.

3 Carlson TH, Atencio AC, Simon TL: Comparison of the behaviour in vivo of two molecular forms of antithrombin III. Biochem J 1985; 225:557-564.
4 Peterson $\mathrm{CB}$, Blackburn $\mathrm{MN}$ : Isolation and characterization of an antithrombin III variant with reduced carbohydrate content and enhanced heparin binding. J Biol Chem 1985; 260:610-615.

5 Brennan SO, George PM, Jordan RE: Physiological variant of antithrombin III lacks carbohydrate sidechain at ASN 135. FEBS Lett 1987;219:431-436.
6 Picard V, Ersdal-Badju E, Bock SC: Partial glycosylation of antithrombin III asparagine-135 is caused by the serine in the third position of its $\mathrm{N}$-glycosylation consensus sequence and is responsible for production of the $\beta$-antithrombin III isoform with enhanced heparin affinity. Biochemistry 1995;34:8433-8440.

7 Frebelius S, Isaksson S, Swedenborg J: Thrombin inhibition by antithrombin III on the subendothelium is explained by the isoform AT $\beta$. Arterioscler Thromb Vasc Biol 1996;16:12921297. 
8 Swedenborg $\mathrm{J}$ : The mechanism of action of $\alpha$ and $\beta$-isoforms of antithrombin. Blood Coagul Fibrinolysis 1998;9(suppl 3):S7-S10.

9 Frebelius S, Hedin U, Swedenborg J: Thrombogenicity of the injured vessel wall - Role of antithrombin and heparin. Thromb Haemost 1994;71:147-153.

10 Witmer MR, Hatton MW: Antithrombin III- $\beta$ associates more readily than antithrombin III- $\alpha$ with uninjured and de-endothelialized aortic wall in vitro and in vivo. Arterioscler Thromb 1991;11:530-539.

11 Turk B, Brieditis I, Bock SC, Olson ST, Björk I: The oligosaccharide side chain on Asn-135 of $\alpha$-antihrombin, absent in $\beta$-antithrombin, decreases the heparin affinity of the inhibitor by affecting the heparin-induced conformational change. Biochemistry 1997;36:6682-6691.

12 Römisch J, Feussner A, Stauss H: Antithrombin III- $\alpha$ and $-\beta$ : Inhibition characteristics of plasmatic proteases and inactivation by elastase. Blood 1998; 10:3407.

13 Bick RL: Disseminated intravascular coagulation: Pathophysiological mechanism and manifestations. Semin Thromb Hemost 1998;24: 19-27.

14 Vervloet MG, Thijs LG, Hack EH: Derangements of coagulation and fibrinolysis in critically ill patients with sepsis and septic shock. Semin Thromb Hemost 1998;24:33-45.

15 Penner JA: Disseminated intravascular coagulation in patients with multiple organ failure of non-septic origin. Semin Thromb Hemost 1998;24:45-53.

16 Nielsen JD: The effect of antithrombin on the systemic inflammatory response in disseminated intravascular coagulation. Blood Coagul Fibrinolysis 1998;9(suppl 3):S11-S15.

17 Inthorn D, Hoffmann JN, Hartl WH, Mühlbayer D, Jochum M: Antithrombin supplementation in severe sepsis: Beneficial effects on organ dysfunction. Shock 1997;8:328-334.

18 Inthorn D, Hoffmann JN, Hartl WH, Mühlbayer D, Jochum M: Effect of antithrombin supplementation on inflammatory response in sepsis. Shock 1998;10:90-96.
19 Eisele B, Lamy M: Clinical experience with antithrombin III concentrates in critically ill patients with sepsis and multiple organ failure. Semin Thromb Hemost 1998;24:71-81.

20 Eisele B, Lamy M, Thijs LG, Keinecke HO, Schuster HP, Matthias FR, Fourrier F, Heinrichs H, Delvos U: Antihrombin III in patients with severe sepsis: A randomized, placebo-controlled, double-blind multicenter trial plus a meta-analysis of all randomized, placebo-controlled, double-blind trials with antithrombin III in severe sepsis. Intensive Care Med 1998; 24:663-672.

21 Ilias W, List W, Decruyenaere J, Lignian H, Knaub S, Schindel F, Keinecke HO, Heinrichs H, Thijs LG: Antithrombin III in patients with severe sepsis: A pharmacokinetic study. Intensive Care Med 2000;26:704-715.

$22 \mathrm{Xu}$ Y: Capillary electrophoresis. Anal Chem 1993;65:425-433.

23 Szökö E: Protein and peptide analysis by capillary zone electrophoresis and micellar electrokinetic chromatography. Electrophoresis 1997; 18:74-81.

24 Petersson M, Walhagen K, Nilsson A, Wahlund KG, Nilsson S: Separation of a bioactive peptide and its oligomeric forms by micellar electrokinetic chromatography. J Chromatogr A 1997;769:301-306.

25 Noroski JE, Mayo DJ, Moran M: Determination of the enantiomer of a cholesterol-lowering drug by cyclodextrin-modified micellar electrokinetic chromatography. J Pharm Biomed Anal 1995; 13:45-52.

26 Dönges R, Römisch J, Stauss H, Brazel D: Separation of antithrombin III variants by cyclodextrin-modified micellar electrokinetic chromatography. J Chromatogr A 2001;924:307313.
27 Buchacher A, Schulz P, Choromanski J, Schwinn H, Josic D: High-performance capillary electrophoresis for in-process control in the production of antithrombin III and human factor IX. J Chromatogr A 1998;802:355-366.

28 Bayston TA, Tripodi A, Mannucci PM, Thompson E, Ireland H, Fitches AC, Hananeia L, Olds RJ, Lane DA: Familial overexpression of $\beta$ antithrombin caused by an Asn135Thr substitution. Blood 1999;93:4242-4247.

29 Warren BL, Eid A, Singer P, Pillay SS, Carl P, Novak I, Chalupa P, Atherstone A, Penzes I, Kubler A, Knaub S, Keinecke HO, Heinrichs H, Schindel F, Juers M, Bone RC, Opal SM: Caring for the critically ill patient. High-dose antithrombin III in severe sepsis: A randomized controlled trial. JAMA 2001;286:18691878

30 Straub H, Risse U, Braun BE, Schlösser S, Barth J, Drews S, May B: In-vivo recovery at antithrombin III substitution. Arzneimitteltherapie 1989;1:6-9.

31 Römisch J, Henkel G, Müller HG, Feussner A, Stauss $\mathrm{H}$ : Comparative in vitro investigation of four antithrombin III concentrates. Thromb Haemost 1997;78:2117.

32 Hellstern P, Moberg U, Ekblad M, Anders CU, Faller B, Müller S: In vitro characterization of antithrombin III concentrates - A single-blind study. Haemostasis 1995;25:193-201.

33 Gray E, Walker AD, Heath AB: A collaborative study to establish the 2nd international standard for antithrombin III concentrate. Thromb Haemost 1999;82:46-50.

34 Fuhge P, Gratz P, Geiger H: Modern methods of the manufacture of coagulation factor concentrates. Transfus Sci 1990;11:23S-33S.

35 Hoffman DL: Purification and large-scale preparation of antithrombin III. Am J Med 1989;87:23S-26S.

36 Lebing WR, Hammond DJ, Wydick JE, Baumbach GA: A highly purified antithrombin III concentrate prepared from human plasma fraction IV-1 by affinity chromatography. Vox Sang 1994;67:117-124. 